\title{
Glycoprotein extraction from Laminaria japonica promotes IEC-6 cell proliferation
}

\author{
HIROE GO, HYE-JUNG HWANG and TAEK-JEONG NAM \\ Faculty of Food Science and Biotechnology, Pukyong National University 599-1, \\ Daeyeon 3-Dong, Nam-gu, Pusan 608-737, Republic of Korea
}

Received July 24, 2009; Accepted September 2, 2009

\section{DOI: 10.3892/ijmm_00000298}

\begin{abstract}
The brown alga Laminaria japonica is frequently consumed in Korea, Japan and China, and has been used for more than a thousand years as a drug in traditional Chinese medicine. In this study, we isolated a novel glycoprotein from L. japonica that stimulates the growth of the IEC-6 normal murine intestinal epithelial cells. We also identified the mechanism by which this glycoprotein, referred to as LJGP, stimulates cell growth. After $24 \mathrm{~h}$ of exposure to LJGP, cell proliferation increased in a dose-dependent manner. To further explore the mechanism associated with LJGPinduced cell proliferation, we treated cells for various times with LJGP. We focused on the epidermal growth factor receptor (EGFR) signaling pathway, which is involved in the regulation of cellular proliferation and differentiation, during LJGP-induced cell growth. The results showed that LJGP induced EGFR and Akt activation. Furthermore, LJGP stimulated Shc/Grb2 binding and ERK activation, but inhibited JNK phosphorylation. These results indicate that LJGP stimulates gastrointestinal cell growth by activating the EGFR signaling pathway.
\end{abstract}

\section{Introduction}

Algae, including Laminaria, Chlorophyta, and Rhodophyta, have a long history of use in the diets of Pacific and Asian cultures compared to those of Europe, Canada, and the US (1). The biological activities of aqueous extracts from marine algae have been investigated, and some extracts possess potential medicinal agents. One of these algae, the brown alga Laminaria japonica, is commonly consumed in Korea, Japan, and China, and has been used for more than 1,000 years as a drug in traditional Chinese medicine. Fucoidan extracted from L. japonica has diverse biological properties, including anticoagulative and antioxidative activities (2-4), and enhances

Correspondence to: Dr Taek-Jeong Nam, Faculty of Food Science and Biotechnology, Pukyong National University 599-1, Daeyeon 3-Dong, Nam-gu, Pusan, 608-737, Republic of Korea

E-mail: namtj@pknu.ac.kr

Key words: seaweeds, glycoprotein, Laminaria japonica, Ras/Raf/MAPK pathway, PI3k/Akt pathway, epidermal growth factor receptor lipid metabolism. In Huh7 hepatoma cells, fucoidan inhibits cell proliferation through the downregulation of CXCL12 (5). Low-molecular-weight fucoidan extracted from L. japonica may have antioxidant activity (4). However, the protein moiety of L. japonica has not been investigated thoroughly. Because L. japonica contains $60.9 \%$ carbohydrate and $10.3 \%$ protein (6), we assumed that its medicinal effects are mainly due to the carbohydrate or protein content. Therefore, we extracted functional components, especially glycoprotein, from $L$. japonica and examined its functions.

Cell proliferation is dependent on intracellular signal transduction mediated by enzyme-linked receptors, such as tyrosine kinase receptors. When receptors are activated by phosphorylation, proteins with an src homology 2 (SH2) domain bind to phosphorylated receptors. Growth factor receptor-bound protein 2 (Grb2) and Shc also contain SH2 domains. Therefore, these proteins combine tyrosine kinase receptors with Ras, which translocates signals from extracellular to intracellular spaces when mitogen-activated protein kinase (MAPK) is activated. Various extracellular stimuli, including growth factors, hormones, osmolarity shock, stress, and elevated temperature, trigger phosphorylation cascades that utilize MAPK (7-14). MAPK pathways, major signaling cascades downstream of the activated epidermal growth factor receptor (EGFR), are involved in the regulation of cellular proliferation and differentiation. Once activated, MAPK translocates signals to the nucleus, where it presumably regulates the expression of different transcription factors (15).

Regarding intracellular signal transduction mediated by tyrosine kinase receptors phosphatidylinositol 3-kinase (PI3k) also promotes cell growth by phosphorylating Akt, also known as protein kinase B (PKB). The PI3k-Akt pathway is a major intracellular signaling module that regulates multiple cellular processes, including cell proliferation, survival, and cellular responses to insulin and nutrients (16-18). In the PI3k-Akt pathway, growth factors activate PI3k via tyrosine kinase receptors, and activated PI3k phosphorylates phosphatidylinositol 4,5-bisphosphate $(\mathrm{PI}(4,5) \mathrm{P} 2)$, converting $\mathrm{PI}(4,5) \mathrm{P} 2$ to $\mathrm{PI}(3,4,5) \mathrm{P} 3$, a lipid second messenger (19). Akt binds to $\mathrm{PI}(3,4,5) \mathrm{P} 3$ and changes conformation following phosphorylation by 3-phosphoinositide-dependent protein kinase-1 (PDK1). Activated Akt phosphorylates numerous substrates that are involved in various cellular functions $(20,21)$.

Although chemotherapeutic agents, either alone or in combination, are used to treat a variety of diseases or cancers, 


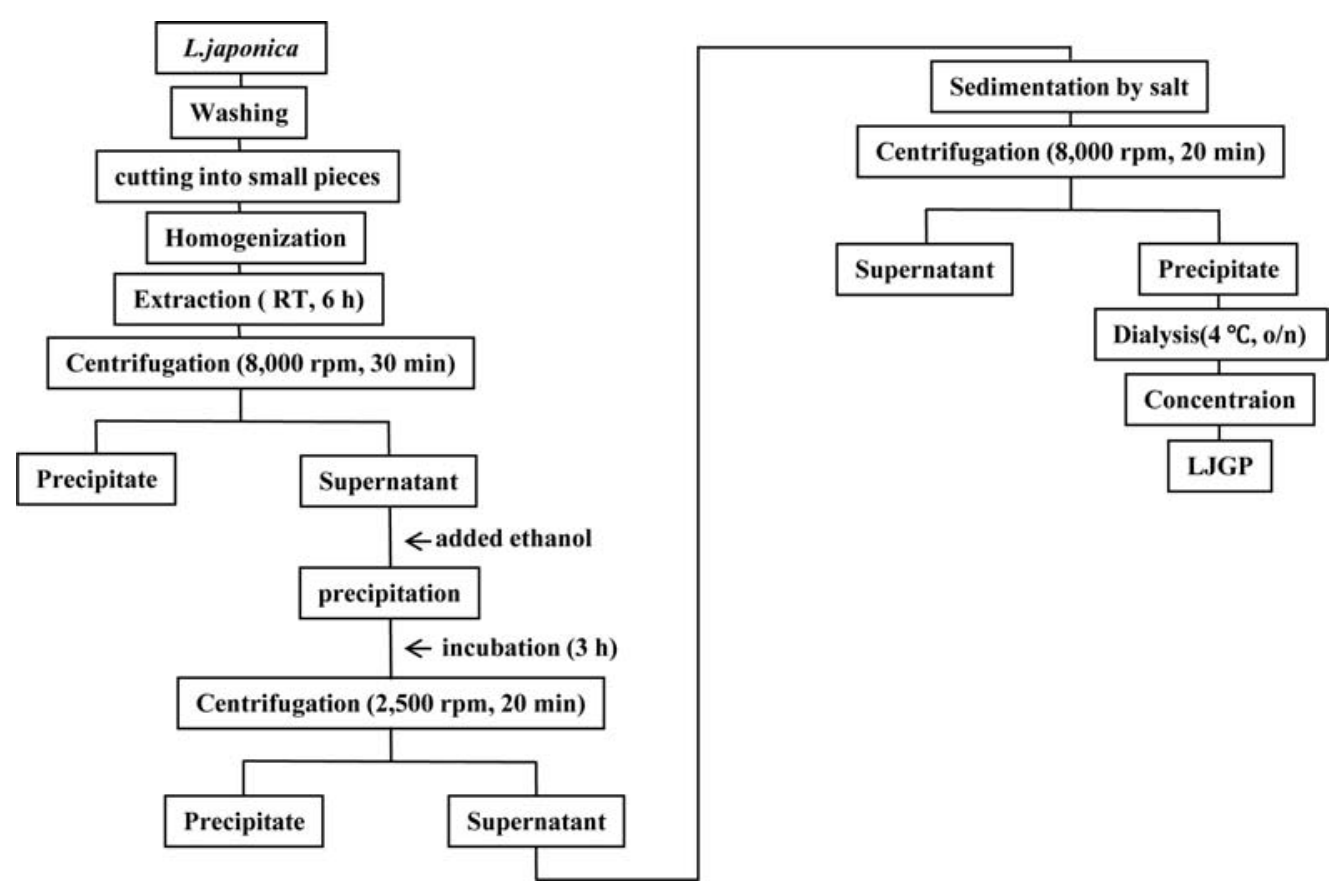

Figure 1. Schematic diagram illustrating the method described in this study to obtain glycoproteins from L. japonica.

these treatments often damage normal tissues. Therefore, strategies for preventing normal cell death induced by therapeutic drugs would be very useful in clinical practice. In this study, we used the normal murine small intestinal epithelial cell line IEC-6 to show that glycoprotein from $L$. japonica (LJGP) has promotive effects on the proliferation of these cells. Furthermore, we elucidated the intracellular mechanism involved in LJGP-induced proliferation of IEC-6 cells. We focused on the EGF signaling pathway, which is involved in the regulation of cellular proliferation and differentiation, during LJGP-induced cell growth.

\section{Materials and methods}

Glycoprotein preparation from Laminaria japonica (LJGP). L. japonica was harvested from the coast of Gijang, Busan, South Korea, in May 2008. The sample was washed several times with tap water to remove salt and visible epiphytes and stored at $-20^{\circ} \mathrm{C}$ until use. The sample $(160 \mathrm{~g})$ was then cut into small pieces and steeped in 11 of distilled water for $6 \mathrm{~h}$ at room temperature. The aqueous extract was clarified by centrifugation and subsequent filtration through Advantec No. 3 filter paper (Advanced MFS, Inc., Dublin, CA, USA) to remove insoluble materials. The filtrate was then mixed with three volumes of ethanol to precipitate the polysaccharide. The precipitated polysaccharide was removed by filtration, the filtrate was condensed, and ammonium sulfate was added to a final concentration of $80 \%$ to precipitate the glycoprotein. The ammonium sulfate-conjugated glycoprotein was then dialyzed against distilled water. Insoluble precipitates were removed by centrifugation and then the supernatant was concentrated using an evaporator. The glycoprotein from L. japonica (LJGP) was stored until further use (Fig. 1).

Cell culture. Rat small intestine epithelial cells (IEC-6, ATCC CRL-1592) were obtained from the American Type
Culture Collection (Rockville, MD, USA). The cells were cultured in Dulbecco's modified Eagle's medium (DMEM) supplemented with $10 \%$ fetal bovine serum (HyClone, Inc., South Logan, UT, USA) and antibiotics. The cultures were maintained in a humidified incubator at $37^{\circ} \mathrm{C}$ under an atmosphere containing $5 \% \mathrm{CO}_{2}$, and the medium was replaced every other day.

Cell proliferation assay. The effects of various LJGP concentrations on cell proliferation were determined colorimetrically after $24 \mathrm{~h}$ using the 3-(4,5-dimethylthiazol-2-yl)5-(3-carboxymethoxy-phenyl)-2-(4-sulfonyl)-2H-tetrazolium (MTS) assay with Cell Titer 96 Aqueous One Solution Reagent (Promega, Madison, WI, USA). Cells were seeded onto 96-well plates at $2 \times 10^{4}$ cells per well. After $24 \mathrm{~h}$ of incubation, cells were maintained in serum-free medium (SFM) for $12 \mathrm{~h}$. The medium was replaced with fresh SFM medium containing LJGP, and the cells were incubated for an additional $24 \mathrm{~h}$. Cells were exposed to MTS assay solution at $37^{\circ} \mathrm{C}$ for $30 \mathrm{~min}$, and the optical density at $490 \mathrm{~nm}$ was measured using a microplate reader. The OD490 values of control cells were designated as $100 \%$.

SDS-polyacrylamide gel electrophoresis (SDS-PAGE). LJGP was analyzed by SDS-PAGE on $15 \%$ gels according to the method of Laemmli (22). After electrophoresis, gels were subjected to Coomassie brilliant blue (CBB) and silver staining for protein bands, and periodic acid-Schiff (PAS) staining for glycoprotein bands (GelCode glycoprotein staining kit, Pierce Co., Ltd., Rockford, IL).

Immunoprecipitation analysis of EGFR-related signaling proteins. Cells were plated onto $100-\mathrm{mm}$ dishes at a density of $2 \times 10^{5}$ cells $\mathrm{ml}^{-1}$ and cultured to $80 \%$ confluence at $37^{\circ} \mathrm{C}$. Cells were then incubated for $24 \mathrm{~h}$ in SFM or SFM containing $20 \mu \mathrm{g} \mathrm{ml}^{-1}$ LJGP. After stimulation with EGF (100 ng ml-1), 

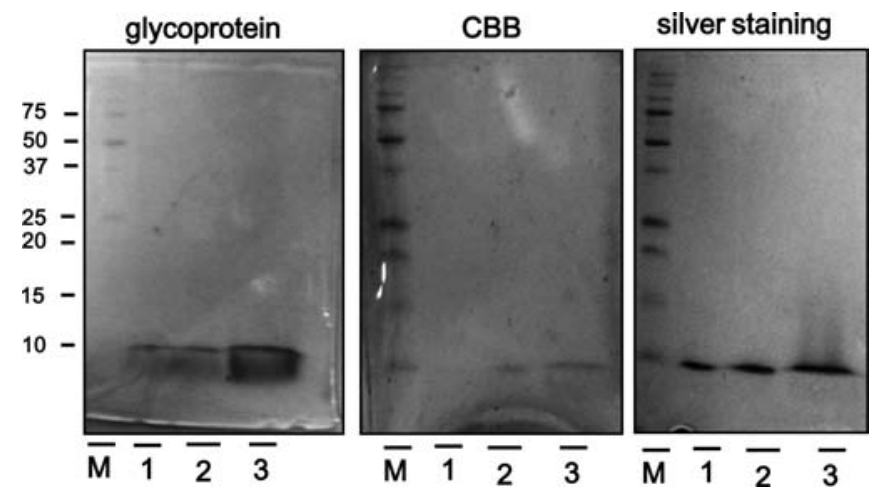

Figure 2. The electrophoresis profiles of LJGP. Each extract $(100 \mu \mathrm{g})$ was applied to a $15 \%$ polyacrylamide gel and stained with periodic acid-Schiff, Coomassie blue and silver. 1, water extract; 2, ethanol extract; 3, LJGP.

cells were washed in cold phosphate buffer solution, lysed with cold immunoprecipitation buffer (10 mM Tris- $\mathrm{HCl}, \mathrm{pH} 7.4$, $150 \mathrm{mM} \mathrm{NaCl}$, and $1 \% \mathrm{HP}-40$ ) containing protease inhibitors, and centrifuged at $15,000 \mathrm{x} \mathrm{g}$ for $15 \mathrm{~min}$. The resulting supernatant fraction was incubated overnight with primary antibodies (anti-EGFR and anti-Shc) with agitation at $4^{\circ} \mathrm{C}$. Protein A-Sepharose beads (Sigma, St. Louis, MO, USA) were then added, and the mixture was incubated for $2 \mathrm{~h}$ to capture the immunocomplex. The beads were collected, washed with immunoprecipitation buffer, and boiled to elute the immunocomplex. The eluted proteins were analyzed by SDSPAGE followed by Western blotting with specific antibodies.

Western blots. Proteins (50 $\mu \mathrm{g}$ ) were separated using 7.5-12.5\% SDS-PAGE and transferred to a polyvinylidene fluoride (PVDF) membrane (Millipore, Billerica, MA, USA). The membranes were blocked with $1 \%$ bovine serum albumin (BSA) in TBS-T (10 mM Tris- $\mathrm{HCl}, 150 \mathrm{mM} \mathrm{NaCl}, \mathrm{pH} 7.5$, $0.1 \%$ Tween-20) and then incubated overnight with the indicated primary antibodies (diluted 1:1,000) in TBS-T containing $1 \%$ BSA with gentle shaking at $4^{\circ} \mathrm{C}$. The secondary antibody was a peroxidase-conjugated goat anti-mouse or rabbit antibody (diluted 1:10,000). Signals were detected using an ECL Western blotting kit (Amersham, Piscataway, NJ, USA).

Statistical analysis. Multiple mean values were compared for significance using analysis of variance (ANOVA) with SPSS statistical software. Values of $p<0.05$ were considered significant.

\section{Results}

Effect of LJGP on IEC-6 cell proliferation. The glycoprotein extracts from L. japonica (Fig. 1) were subjected to SDSPAGE (Fig. 2). After electrophoresis, the gels were subjected to $\mathrm{CBB}$ and silver staining for protein and PAS staining for glycoprotein. We confirmed the presence of a glycoprotein band at $\sim 10 \mathrm{kDa}$ in each lane (Fig. 2) and named it LJGP. LJGP was used in the following assays with the normal murine intestinal epithelial cell line IEC-6. After exposure of the cells to $0-20 \mu \mathrm{g} \mathrm{ml}^{-1}$ LJGP for $24 \mathrm{~h}$, the cell number increased in a dose-dependent manner (Fig. 3). The cells were

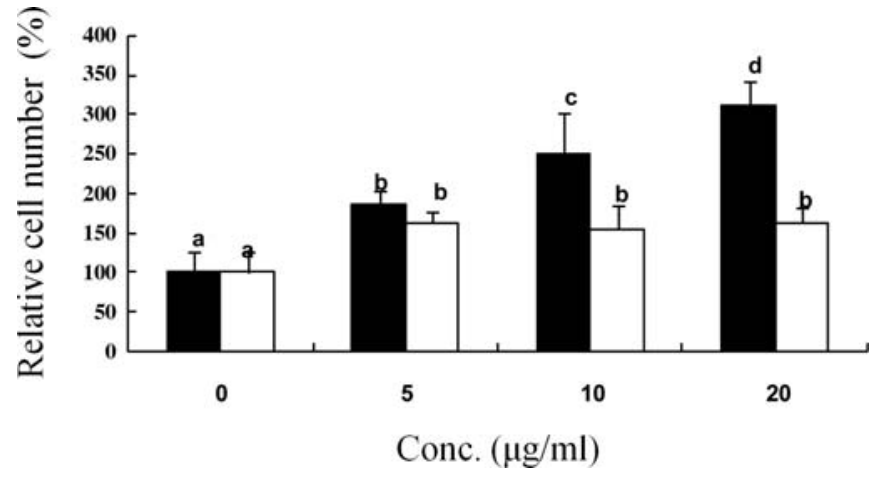

Figure 3. Effect of LJGP treatment on the growth of the IEC-6 small intestine epithelial cells. The cells were treated with the indicated concentrations of LJGP (black bar) and bovine serum albumin (BSA) (white bar), and the relative cell number was determined using the MTS assay. Values are the means $\pm S D ; n=6(p<0.01)$.

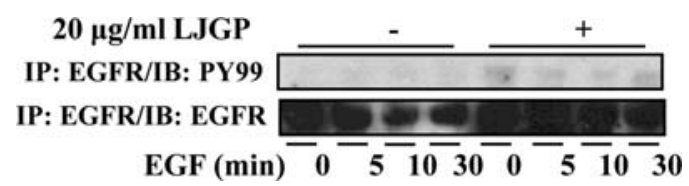

Figure 4. Tyrosine phosphorylation of EGFR in response to LJGP treatment. Cells were treated as mentioned in Materials and methods, protein was extracted with lysis buffer and the intracellular protein expression was analyzed by immunoprecipitaion and Western blot analysis. One representative gel from three separate experiments is shown.

also exposed to BSA as a control to confirm the effect of LJGP on IEC-6 cell proliferation. Although BSA treatment slightly stimulated cell growth, the effect was probably due to the protein content of the medium. Therefore, these results demonstrate that LJGP has a consistent acceleration on cell proliferation.

LJGP stimulates MAPK activation. Since LJGP induces IEC-6 cell proliferation (Fig. 3), we attempted to determine whether LJGP-induced proliferation was linked to the EGFR signaling pathway, which stimulates cell differentiation and proliferation. IEC-6 cells were treated with LJGP and stimulated with $100 \mathrm{ng} \mathrm{ml}^{-1}$ EGF for various time periods. LJGP treatment $\left(20 \mu \mathrm{g} \mathrm{ml}^{-1}\right)$ for $24 \mathrm{~h}$ stimulated EGFR phosphorylation as compared to control cells (Fig. 4). EGFR, a tyrosine kinase receptor, translocates growth signaling from extracellular to nuclear using signal transduction pathways, including the Ras/Raf/MAPK and PI3k/Akt pathways (23). These signaling pathways are known to be important for cell differentiation and proliferation. The Ras/Raf/MAPK pathway is specifically related to cell proliferation and survival.

We also studied the phosphorylation of Shc, an adaptor protein which is known to interact with Grb2 and is involved in signal transduction from the EGFR receptor to the nucleus. We treated IEC-6 cells with LJGP and stimulated them with $100 \mathrm{ng} \mathrm{ml}^{-1}$ EGF for various time periods. LJGP treatment increased the phosphorylation of Shc in a time-dependent manner (Fig. 5). We also attempted to determine the effect of LJGP on the interaction observed between Shc and Grb2. We detected increased Grb2 binding as compared to control cells 


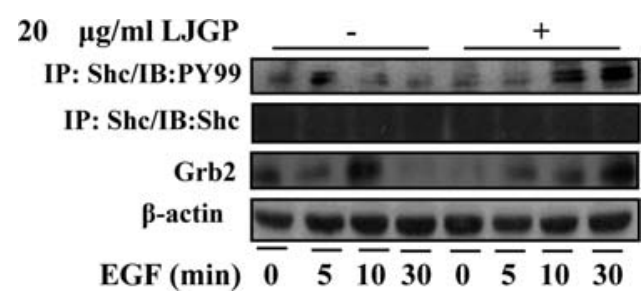

Figure 5. The effect of LJGP on the expression of Shc and Grb2. Cells were treated as indicated in Materials and methods, protein was extracted with lysis buffer and the intracellular protein expression was analyzed by immunoprecipitaion and Western blot analysis. One representative gel from three separate experiments is shown.

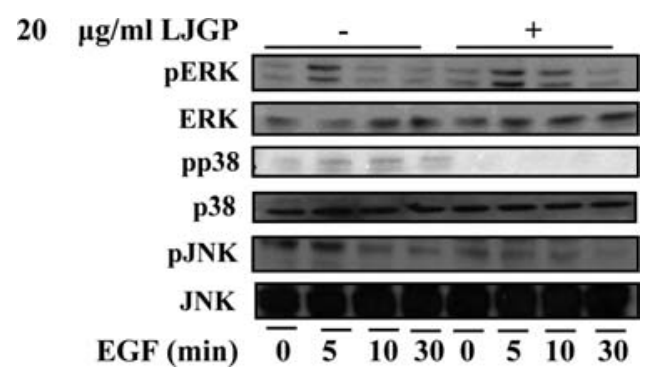

Figure 6. Effect of LJGP on MAPK signaling pathway. Cells were treated as indicated in Materials and methods, protein was extracted with lysis buffer and the intracellular protein expression was analyzed by immunoprecipitaion and Western blot analysis. One representative gel from three separate experiments is shown.

(Fig. 5). Interaction between Shc and Grb2 translocates signals to MAPK. Therefore, we examined the phosphorylation levels of MAPKs, including the extracellular signal-regulated kinase (ERK1/2), p38, and c-Jun N-terminal kinase (JNK). Cells were incubated with $20 \mu \mathrm{g} \mathrm{ml}^{-1}$ LJGP for $24 \mathrm{~h}$ and stimulated with $100 \mathrm{ng} \mathrm{ml}^{-1}$ EGF at various times. In LJGPtreated cells, ERK1/2 phosphorylation increased 5 min after EGF stimulation (Fig. 6). However, in untreated cells, the phosphorylation decreased significantly in $10 \mathrm{~min}$. Furthermore, the phosphorylation of p38 and JNK decreased in the LJGPtreated cells as compared to untreated cells (Fig. 6).

LJGP induces phosphorylation in the PI3K-Akt pathway. The $\mathrm{PI} 3 \mathrm{~K} / \mathrm{Akt}$ pathway is mainly associated with cell growth. We studied the involvement of this pathway in LJGP-induced IEC-6 cell proliferation. PI3k is activated by the growth factor EGF (24), and following activation the recruitment of Akt to the membrane was observed $(25,26)$. We examined whether LJGP stimulates the phosphorylation of p85, a subunit of PI3k. Cells were treated with $20 \mu \mathrm{g} \mathrm{ml}^{-1}$ LJGP for $24 \mathrm{~h}$ and stimulated with $100 \mathrm{ng} \mathrm{ml}^{-1} \mathrm{EGF}$ for various time periods. LJGP caused increased phosphorylation of $\mathrm{p} 85$ (Fig. 7). Moreover, Akt phosphorylation was enhanced in cells treated with LJGP (Fig. 7).

\section{Discussion}

Marine algae, such as seaweeds, are amply present in seawater. Seaweeds contain many useful components and physiologically active substances that remain unidentified $(27,28)$.

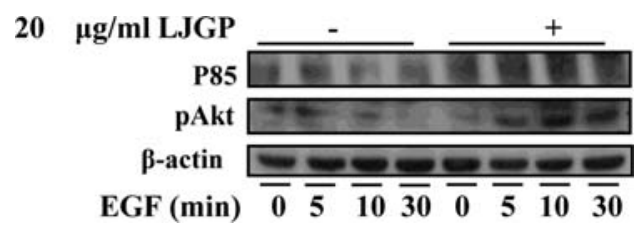

Figure 7. Effect of LJGP on the activation of PI3K and Akt. Cells were treated as indicated in Materials and methods, protein was extracted with lysis buffer and the intracellular protein expression was analyzed by immunoprecipitaion and Western blot analysis. One representative gel from three separate experiments is shown.

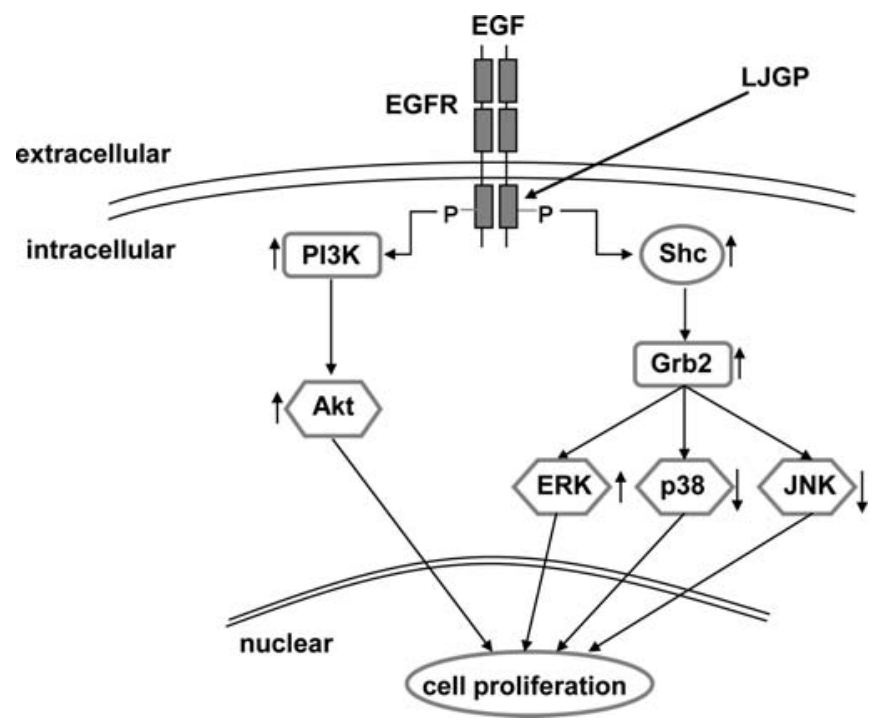

Figure 8. A schematic model of the LJGP-induced signaling pathways. LJGP induced IEC-6 cells proliferation via two signal pathways, the Ras/Raf/MAPK and PI3k/Akt pathways.

Carrageenan and alginic acid, which are isolated from red and brown algae, are known to lower cholesterol levels in the serum and liver (4). We separated an extract from Laminaria japonica (Fig. 1) and used SDS-PAGE to confirm that it is a glycoprotein, which we designated LJGP (Fig. 2). To our knowledge, this is the first report on the proliferative activities of this glycoprotein on small murine intestinal epithelial cells (IEC-6). The results from the MTS assay demonstrated that LJGP stimulated cell growth in a dosedependent manner (Fig. 3).

The stimulation of cell proliferation is dependent on multiple signaling pathways. In this study, we focused on the EGFR signaling pathway. Expression of EGFR was detected in different cell types, including epithelial, mesenchymal, and nerve cells. Its activation leads to cell differentiation and proliferation. Our results showed that LJGP induced EGFR phosphorylation (Fig. 4). Activated EGFR leads to the phosphorylation of specific tyrosine residues within the EGFR cytoplasmic domain that acts as a docking site for effector molecules, triggering downstream signaling pathways (29). One of the downstream signaling pathways is the Ras/Raf/MAPK pathway. The MAPK family in mammalian cells includes extracellular signal-regulated kinase- 1 and kinase-2 (ERK-1/2), the c-Jun $\mathrm{NH}_{2}$ terminal kinase (JNK), and p38 (30). In accordance with the LJGP-induced cell 
proliferation, ERK-1/2 was activated after exposure to LJGP, an important mediator that regulates cell growth and differentiation (Fig. 6). In contrast, decreased phosphorylation of JNK and p38 was observed (Fig. 6), phenomena that are associated with cell death and oxidative stress. For most cell types, EGFR has been proposed to mediate Ras/Raf/ERK activation and the ERK pathway was implicated in mitogenic signal transduction in response to several stimuli (31-34). Moreover, we confirmed the interaction of the adaptor protein Shc and Grb2 (Fig. 5). The interaction of Shc and Grb2 is an essential step following EGFR activation in MAPK signal translocation.

Our results indicate that EGFR activation also contributes to LJGP-induced proliferation through the activation of the PI3k/Akt pathway. The PI3K/Akt pathway has been identified as a key player in cell survival $(35,36)$. Akt also functions in normal growth as seen in Akt-knockout mice, which show retarded growth (37). PI3k is activated by EGFR through heterodimerization with ErbB3, which contains a docking site for the p85 subunit of PI3k (38). Once the p85 subunit is positioned, the p110 subunit of PI3k generates phosphatidylinositol 3,4,5-triphosphate (PIP3), which activates Akt (38). Consistent with this model, we detected the phosphorylation of Akt (Fig. 7).

In the present study, we extracted a glycoprotein from L. japonica that not only has anticancer activity (data not shown), but also enhances cell growth in normal intestinal cells. Furthermore, we studied the intracellular mechanisms involved in cell proliferation through the EGFR signaling pathway. The results showed that LJGP induced Akt/ERK activation and downregulated JNK/p38 (Fig. 8). Although further studies are needed to define its interaction on the cell membrane surface, we suggest that LJGP is a potentially useful agent for understanding intestinal function.

\section{Acknowledgements}

This research was part of the project titled 'Development for Novel Biofunctional Protein Source from Marine Algae Produced in the Coastal Area of Busan' funded by the Ministry of Land, Transport and Maritime Affairs, Korea.

\section{References}

1. Yuan YV and Walsh NA: Antioxidant and antiproliferative activities of extracts from a variety of edible seaweeds. Food Chem Toxicol 44: 1144-1150, 2006.

2. Durig J, Bruhn T, Zurborn KH, Gutensohn K, Bruhn HD and Beress L: Anticoagulant fucoidan fractions from Fucus vesiculosus induce platelet activation in vitro. Thromb Res 85: 479-491, 1997.

3. Trento F, Cattaneo F, Rescador R, Porta R and Ferro L: Antithrombin activity of an algal polysaccharide. Thromb Res 102: 457-465, 2001.

4. Wang J, Zhang Q, Zhang Z and Li Z: Synthesized different derivatives of low molecular fucoidan extracted from $L$. japonica and their potential antioxidant activity in vitro. Int J Biol Macromol 44: 379-384, 2009.

5. Nagamine T, Hayakawa K, Kusakabe T, Takada H, Nakazato K, Hisanaga $\mathrm{E}$ and Iha M: Inhibitory effect of fucoidan on Huh7 hepatoma cells through downregulation of CXCL12. Nutr Cancer 61: 340-347, 2009.

6. Cho DM, Kim DS, Lee DS, Kim HR and Pyeun JH: Trace components and functional saccharides in seaweed-1. Changes in proximate composition and trace elements according to the harvest season and places. Bull Korean Fish Soc 28: 49-59, 1995.
7. Ahn NG and Krebs EG: Evidence for an epidermal growth factor-stimulated protein kinase cascade in Swiss 3T3 cells. Activation of serine peptide kinase activity by myelin basic protein kinases in vitro. J Biol Chem 265: 11495-11501, 1990.

8. Ahn NG, Weiel JE, Chan CP and Krebs EG: Identification of multiple epidermal growth factor-stimulated protein serine/ threonine kinases from Swiss 3T3 cells. J Biol Chem 265: 11487-11494, 1990.

9. Freshney NW, Rawlinson L, Guesdon F, Jones E, Cowley S, Hsuan J and Saklatvala J: Interleukin-1 activates a novel protein kinase cascade that results in the phosphorylation of Hsp27. Cell 78: 1039-1049, 1994.

10. Ohmichi M, Sawada T, Kanada Y, Koike K, Hirota K, Miyake A and Saltiel AR: Thyrotropin-releasing hormone stimulates MAP kinase activity in GH3 cells by divergent pathways. Evidence of a role for early tyrosine phosphorylation. J Biol Chem 269: 3783-3788, 1994.

11. Pang L, Decker SJ and Saltiel AR: Bombesin and epidermal growth factor stimulated the mitogen-activated protein kinase through different pathways in Swiss 3T3 cells. Biochem J 89: 283-287, 1993.

12. Pombo CM, Bonventre JV, Avruch J, Woodgett JR, Kyriakis JM and Force T: The stress-activated protein kinases are major c-Jun amino-terminal kinases activated by ischemia and reperfusion. J Biol Chem 269: 26546-26551, 1994.

13. Ray LB and Sturgill TW: Rapid stimulation by insulin of a serine/threonine kinase in 3T3-L1 adipocytes that phosphorylates microtubule-associated protein 2 in vitro. Proc Natl Acad Sci USA 84: 1502-1506, 1987.

14. Rouse J, Cohen P, Trigon S, Morange M, Alonso-Llamazares A, Zamanillo D, Hunt T and Nebreda AR: A novel kinase cascade triggered by stress and heat shock that stimulates MAPKAP kinase- 2 and phosphorylation of the small heat shock proteins. Cell 78: 1027-1037, 1994.

15. Hayashi $H$, Tsuchiya $Y$, Nakayama $K$, Satoh $T$ and Nishida $E$ : Down-regulation of the PI3-kinase/Akt pathway by ERK MAP kinase in growth factor signaling. Genes Cells 13: 941-947, 2008.

16. Cantley LC: The phosphoinositide 3-kinase pathway. Science 296: 1655-1657, 2002.

17. Fruman DA, Meyers RE and Cantley LC: Phosphoinositide kinases. Annu Rev Biochem 67: 481-507, 1998.

18. Katso R, Okkenhaug K, Ahmadi K, White S, Timms J and Waterfield MD: Cellular function of phosphoinositide 3-kinase: implications for development, homeostasis, and cancer. Annu Rev Cell Dev Biol 17: 615-675, 2001.

19. Czech MP: Dynamics of phosphoinositides in membrane retrieval and insertion. Annu Rev Physiol 65: 791-815, 2003.

20. Fresno Vara JA, Casado E, de Castro J, Cejas P, Belda-Iniesta C and Gonsalez-Baron M: PI3K/Akt signaling pathway and cancer. Cancer Treat Rev 30: 193-204, 2004.

21. Liang J and Slingerland JM: Multiple roles of the PI3K/PKB(Akt) pathway in cell cycle progression. Cell Cycle 2: 339-345, 2003.

22. Laemmli UK: Cleavage of structural proteins during the assembly of the head of bacteriophage T4. Nature 227: 680-685, 1970.

23. Scaltriri $\mathrm{M}$ and Baselga J: The epidermal growth factor receptor pathway: a model for targeted therapy. Clin Cancer Res 12: 5268-5272, 2006

24. White MF and Kahn CR: The insulin signaling system. J Biol Chem 269: 1-4, 1994.

25. Dews M, Prisco M, Peruzzi F, Romano G, Morrione A and Baserga R: Domains of the insulin-like growth factor I receptor required for the activation of extracellular signal-regulated kinases. Endocrinology 141: 1289-1300, 2000.

26. White MF: The IRS-signaling system: a network of docking proteins that mediate insulin action. Mol Cell Biochem 182: 3-11, 1998 .

27. Shin HC, Hwang HJ, Kang KJ and Lee BH: An antioxidative and anti-inflammatory agent for potential treatment of osteoarthritis from Ecklonia cava. Arch Pharm Res 29: 165-171, 2006.

28. Wang C and Yang G: Comparison of effects of two kinds of soluble algae polysaccharide on blood lipid, liver lipid, platelet aggregation and growth in rats. Zhonghua Yu Fang Yi Xue Za Ahi 31: 342-345, 1997.

29. Chiu T, Santiskulvong C and Rozengurt E: EGF receptor transactivation mediates ANG II-stimulated mitogenesis in intestinal epithelial cells through the PI3-kinase/Akt/ mTOR/p70S6K1 signaling pathway. Am J Physiol Gastrointest Liver Physiol 288: 182-194, 2004. 
30. Paruchuri S, Hallberg B, Juhas M, Larsson C and Sjölander A: Leukotriene $\mathrm{D}(4)$ activates MAPK through a Ras-independent but PKCepsilon-dependent pathway in intestinal epithelial cells. J Cell Sci 115: 1883-1893, 2002.

31. Dugourd C, Gervais M, Corvol P and Monnot C: Akt is a major downstream target of PI3-kinase involved in angiotensin IIinduced proliferation. Hypertension 41: 882-890, 2003.

32. Eguchi S, Iwasaki H, Ueno H, Frank GD, Motley ED, Eguchi K, Marumo F, Hirata Y, Inagami T: Intracellular signaling of angiotensin II-induced p70 S6 kinase phosphorylation at Ser(411) in vascular smooth muscle cells. Possible requirement of epidermal growth factor receptor, Ras, extracellular signalregulated kinase, and Akt. J Biol Chem 274: 36843-36851, 1999.

33. Greco S, Muscella A, Elia MG, Salvatore P, Storelli C, Mazzotta A, Manca C and Marsigliante S: Angiotensin II activates extracellular signal regulated kinases via protein kinase $\mathrm{C}$ and epidermal growth factor receptor in breast cancer cells. J Cell Physiol 196: 370-377, 2003.
34. Hama K, Ohnishi H, Yasuda H, Ueda N, Mashima H, Satoh Y, Hanatsuka K, Kita H, Ohashi A, Tamada K and Sugano K: Angiotensin II stimulates DNA synthesis of rat pancreatic stellate cells by activating ERK through EGF receptor transactivation. Biochem Biophys Res Commun 315: 905-911, 2004.

35. Kandel ES and Hav N: The regulation and activities of the multifunctional serine/threonine kinase Akt/PKB. Exp Cell Res 253: 210-229, 1999.

36. Parrizas M, Saltiel AR and LeRoith D: Insulin-like growth factor 1 inhibits apoptosis using phosphatidylinositol 3'-kinase and mitogen-activated protein kinase pathways. J Biol Chem 272: 154-161, 1997.

37. Carrie E, McCurdy CE and Cartee GD: Akt2 is essential for the full effect of calorie restriction on insulin-stimulated glucose uptake in skeletal muscle. Diabetes 54: 1349-1356, 2005.

38. Morgan S and Grandis JR: ErbB receptors in the biology and pathology of the aerodigestive tract. Exp Cell Res 315: 572-582, 2008. 